\title{
Impact of irrigation regime on berry development and flavonoids composition in Aragonez (Syn. Tempranillo) grapevine
}

\author{
Olfa Zarrouk ${ }^{\mathrm{a}, *}$, Rita Francisco ${ }^{\mathrm{a}}$, Marta Pinto-Marijuan ${ }^{\mathrm{a}}$, Ricard Brossa ${ }^{\mathrm{c}}$, Raquen Raissa Santos ${ }^{\mathrm{a}}$, \\ Carla Pinheiro $^{a}$, Joaquim Miguel Costa ${ }^{\mathrm{a}, \mathrm{b}}$, Carlos Lopes ${ }^{\mathrm{b}}$, Maria Manuela Chaves ${ }^{\mathrm{a}, \mathrm{b}}$ \\ a Instituto de Tecnologia Quimica e Biologica, Oeiras, Universidade Nova de Lisboa, Portugal \\ ${ }^{\mathrm{b}}$ CBAA, Instituto Superior de Agronomia, Universidade Tecnica de Lisboa, Lisboa, Portugal \\ ' Departament Biologia Vegetal, Facultat de Biologia, Universidad de Barcelona, Spain
}

\section{A R T I C L E I N F O}

\section{Article history:}

Available online 11 July 2012

\section{Keywords:}

Vitis vinifera

Anthocyanins

Proanthocyanidins

Flavonols

ORAC

ABA

\begin{abstract}
A B S T R A C T
In the present study, field grown Aragonez (Syn. Tempranillo) grapevines (Vitis vinifera L.) were subjected to three irrigation regimes (conventional sustained deficit irrigation(DI), regulated deficit irrigation (RDI) and non-irrigated (NI)) during two successive seasons (2007-2008). An integrative study was performed in grape berry skin tissues at four phenological stages of grape berry (pea size, véraison, mid-ripening and full maturation). The accumulation of flavonoid compounds, the profile of accumulation of abscisic acid (ABA) and jasmonic acid (JA) hormones were analysed during grape ripening. The non-enzymatic antioxidant capacity was also characterised. Principal component analysis followed by a between group analysis (PCA-BGA) showed a clear separation already at early stages of grape berry development between the three treatments in both years. The main compounds affected by water availability were proanthocyanidins and flavonols, which increased with irrigation at all phenological stages. In both years, concentrations of anthocyanin at full maturation were observed to be higher in the skin of berries belonging to DI and RDI vines than in NI ones. ABA accumulation was also regulated by the intensity of water stress since early stages of berry development. However, no differences in sugar accumulation were observed between treatments. The present study also shows that climatic conditions, namely temperature, play an important role in the ripening process of grape berries. This was clearly observed in NI vines during both years, in which a decrease in the quality parameters in grape skins is presumably related to high temperature and excessive cluster sunlight exposition more marked in 2007, the hotter year. This supports the crucial role of irrigation in maintaining the cluster microclimate in an optimum range, thus enabling a balanced synthesis of the compounds relevant to wine quality.
\end{abstract}

(c) 2012 Elsevier B.V. All rights reserved.

\section{Introduction}

Traditionally non-irrigated grapevine (Vitis vinifera L.) is widely spread across dry and semi dry regions and is well adapted to the Mediterranean climate (Schultz, 2003). The predicted scenarios for global environmental change suggest that despite its drought tolerance, grapevine growth in the Mediterranean area would be affected (Flexas et al., 2002) with limitations in growth, abnormal ripening and reduced berry quality. Irrigation rises as a solution. Nonetheless, an appropriate balance between vegetative and reproductive development (see review Chaves et al., 2010) is the key to improve winegrape quality in irrigated vineyards. One of the main strategies to deal with this question has been the use of regulated deficit irrigation (RDI) (McCarthy et al., 2002). RDI

\footnotetext{
* Corresponding author. Tel.: +351 214469642; fax: +351214433644.

E-mail address: zolfa@itqb.unl.pt (O. Zarrouk).
}

consists in the addition of water to maintain vine water status within prescribed limits of deficit with respect to maximum water potential in specific phases of grapevine development (Kriedemann and Goodwin, 2003). In red winegrape, the deficit period is generally intended to occur shortly after fruit-set, in order to reduce grapevine vegetative growth (McCarthy, 1997; Keller et al., 2008; Lopes et al., 2011) but also to obtain smaller berries and better cluster exposure, thereby improving sugar and colour accumulation (Matthews and Anderson, 1988; Intrigliolo and Castel, 2010). However, RDI has some implementation difficulties. Having a short period of water stress immediately after berry set is dependent on the soil water available at flowering time, which in turn depends on the amount of winter and early spring rains and on the water used during spring (Lopes et al., 2011).

Grape berry growth and ripening are complex developmental processes. In all growth phases, the very active skin (exocarp) metabolism deeply influences the final characteristics of the berry. The exocarp is the site for the synthesis of major compounds 
that define grape berry quality. One family of such compounds is flavonoids. Among the most important in grape berry are anthocyanins, flavonols and proanthocyanidins. Anthocyanins are the major contributors of red grape and wines and are the most abundant flavonoids in grape skin. Proanthocyanidins, known also as tannin, are responsible for the astringency, bitterness and structure of wines and are most abundant in seeds. Flavonols are only present in grape skin and are considered together with anthocyanins the most important flavonoids that accumulate in this tissue. Flavonols and anthocyanins react and produce more stable pigments in red wines (Rodriguez Montealegre et al., 2006). Flavonoid concentrations depend on the variety and are influenced by viticultural management and environmental stresses (see review by Chaves et al., 2010; Lovisolo et al., 2010; Dai et al., 2011).

Several reports showed that regulating grapevine water status is a powerful tool to manage the amount of these compounds (Kennedy et al., 2002) through an indirect effect on berry size, and therefore the skin to pulp ratio, which increases in the smaller berries of vines subjected to water deficits (Bravdo et al., 1985; Kennedy et al., 2002). However, Roby et al. (2004) reported a direct and possibly greater direct effect of water deficit on skin proanthocyanidin and anthocyanin contents. Supporting this observation, different proteomic and transcriptomic studies in berries from grapevines subjected to water stress reported an effect on the metabolic pathway of secondary metabolites (Grimplet et al., 2009; Deluc et al., 2009; Castellarin et al., 2007a). In recent years, flavonoid compounds attracted much interest due to their antioxidant proprieties and their potentially human health benefit (Yilmaz and Toledo, 2004; Nassiri-Asl and Hosseinzadeh, 2009; Iriti and Faoro, 2009). Although several studies reported the antioxidant activities of grape berry compounds (Kedage et al., 2007; Ruberto et al., 2007; Poudel et al., 2008; Gatti et al., 2011), the literature lacks information on how water deficit modulates these activities.

The grape berry is a non-climacteric fruit, and several reports showed the role of hormones, namely abscisic acid (ABA) on the regulation of ripening (Davies et al., 1997; Deluc et al., 2009; Owen et al., 2009; Wheeler et al., 2009). Berry ABA concentration increases at the beginning of véraison (Wheeler et al., 2009; Owen et al., 2009) suggesting that ABA has a role at the onset of ripening. Moreover, exogenous ABA treatments enhanced several processes involved in berry ripening, such as anthocyanin and sugar accumulations in grape berry (Owen et al., 2009; Koyama et al., 2010). Reports of Deluc et al. (2009) showed that Cabernet Sauvignon vines subjected to water deficit almost doubled ABA concentrations at verraison and that the ABA metabolic pathway was altered by such stress. In what regards other hormones, jasmonic acid (JA) seems to have a role at early stage of cell division and expansion in grape berry (Kondo and Fokuda, 2001). Still no reports are available for the effect of water stress in the concentration of JA in grape berries. Nonetheless, there is evidence that jasmonic acid is involved in plant responses to several abiotic and biotic stresses such as drought. It was also demonstrated that jasmonate stimulate tomato and apple fruit ripening (Czapski and Saniewski, 1992) and alter the accumulation of major anthocyanins in $V$. vinifera cell culture (Curtin et al., 2003). Recently it was shown that JA induced anthocyanin biosynthesis in Arabidopsis (Shan et al., 2009).

Despite the progress made by grapevine research community in the last years (Castellarin et al., 2007a,b; Deluc et al., 2009), it is clear that there is still much work to be done to fully unravel the impact of water deficit on grape berry metabolism.

In the present study we studied the effect of water availability on grape berry skin composition collected at four phenological stages during berry development (pea size, véraison, mid-ripening and full maturation). This study included different quality parameters (anthocyanins, proanthocyanidins and flavonols) and putative hormonal berry ripening signalling. We aimed at identifying which compounds were predominantly affected by water availability and the timing of these changes that may have an impact on the final quality of the berries.

\section{Materials and methods}

\subsection{Experimental design and climatic conditions}

Experiments were carried out during the 2007 and 2008 seasons in a commercial vineyard, located at Estremoz, Southern Portugal (lat. 38 $51 \_\mathrm{N}$; long. $7^{\circ} 33 \_\mathrm{W}$ ) where the climate is of Mediterranean type, with hot and dry summers and mild rainy winters. The soil is derived from schist with a variable depth (1.0-1.5 m). Soil horizons present a silty clay loam texture with the following average characteristics: clay $34.2 \%$; silt $30.4 \%$; sand $35.4 \%$; organic matter $2.0 \%$; $\mathrm{pH}\left(\mathrm{H}_{2} \mathrm{O}\right) 7.1$.

The eight-year-old grapevines of the red variety Aragonez (syn. Tempranillo) were grafted on 1103 Paulsen rootstock with a spacing of $1.0 \mathrm{~m} \times 2.5 \mathrm{~m}$. Vines were trained on a vertical shoot positioning and spur-pruned on a bilateral Royat Cordon system. The experimental layout was a randomised complete block design with three treatments and three replications per treatment. The elemental plot comprised three adjacent rows (two buffer rows and a central one for data collection) of eight vines each.

Climatic data on air temperature and precipitation (Fig. 1) were obtained from an automatic meteorological station located near the vineyard $\left(38^{\circ} 52^{\prime} \mathrm{N}, 07^{\circ} 31^{\prime} \mathrm{W}\right)$ (COTR, 2008). In term of temperature, 2007 was hotter than 2008. In contrast, 2008 was dryer than 2007.

The three treatments were: conventional sustained deficit irrigation (DI) and regulated deficit irrigation (RDI) and non-irrigated (NI). The drip line was positioned along the row close to the vine trunks and consisted of pressure compensating $2.5 \mathrm{~L} / \mathrm{h}$ emitters at $0.5 \mathrm{~m}$ (DI) and $1.0 \mathrm{~m}$ (RDI) spacing positioned between two adjacent vines. In DI, irrigation started at July 4 th and was stopped at September 3rd in 2007 and in 2008 it started at the July 2nd and stopped at August 29th. RDI irrigation was started at the same dates but it was withheld at 17 th August and at 1 st August respectively in 2007 and in 2008.

Watering was applied according to the crop evapotranspiration $\left(\mathrm{ET}_{\mathrm{C}}\right)$ and soil water content. $\mathrm{ET}_{\mathrm{c}}$ was estimated from the reference evapotranspiration $\left(\mathrm{ET}_{0}\right) . \mathrm{ET}_{0}$ was obtained in an automatic weather station located within the experimental vineyard, using the crop coefficients proposed by Allen et al. (1998). During irrigation, the average fraction of $\mathrm{ET}_{\mathrm{c}}$ applied was $c a$. 0.3. Frequency of water applications was the same for all irrigated treatments and varied from 2 to 5 days. The total amount of water supplied to DI plants was 126 and $140 \mathrm{~mm}$ in 2007 and 2008 respectively (60\% Etc.), while the supply on RDI was $57 \mathrm{~mm}$ in 2007 and $44 \mathrm{~mm}$ in 2008 (30\% Etc.). Standard cultural practices in the region were applied to all treatments. To characterise the vine water status, vine predawn leaf water potential was measured before each sampling date. Measurements were carried out on an adult leaf from six replicate plants from each treatment, using a Scholander pressure chamber (Model 1000; PMS instrument Co., Corvallis, OR, USA).

\subsection{Grape berry analysis}

The analysed berry material was collected along berry development during the summer season of 2007 and 2008 (June-September). Four stages were considered: end of pea size (PS, 7 weeks after anthesis), véraison ( $\mathrm{V}, 9$ weeks after anthesis), mid-ripening (MR, 11 weeks after anthesis) and full maturation (FM, 13 weeks after anthesis).

At each sampling date a representative sample of 50 bunches per treatment was randomly collected from the experimental 

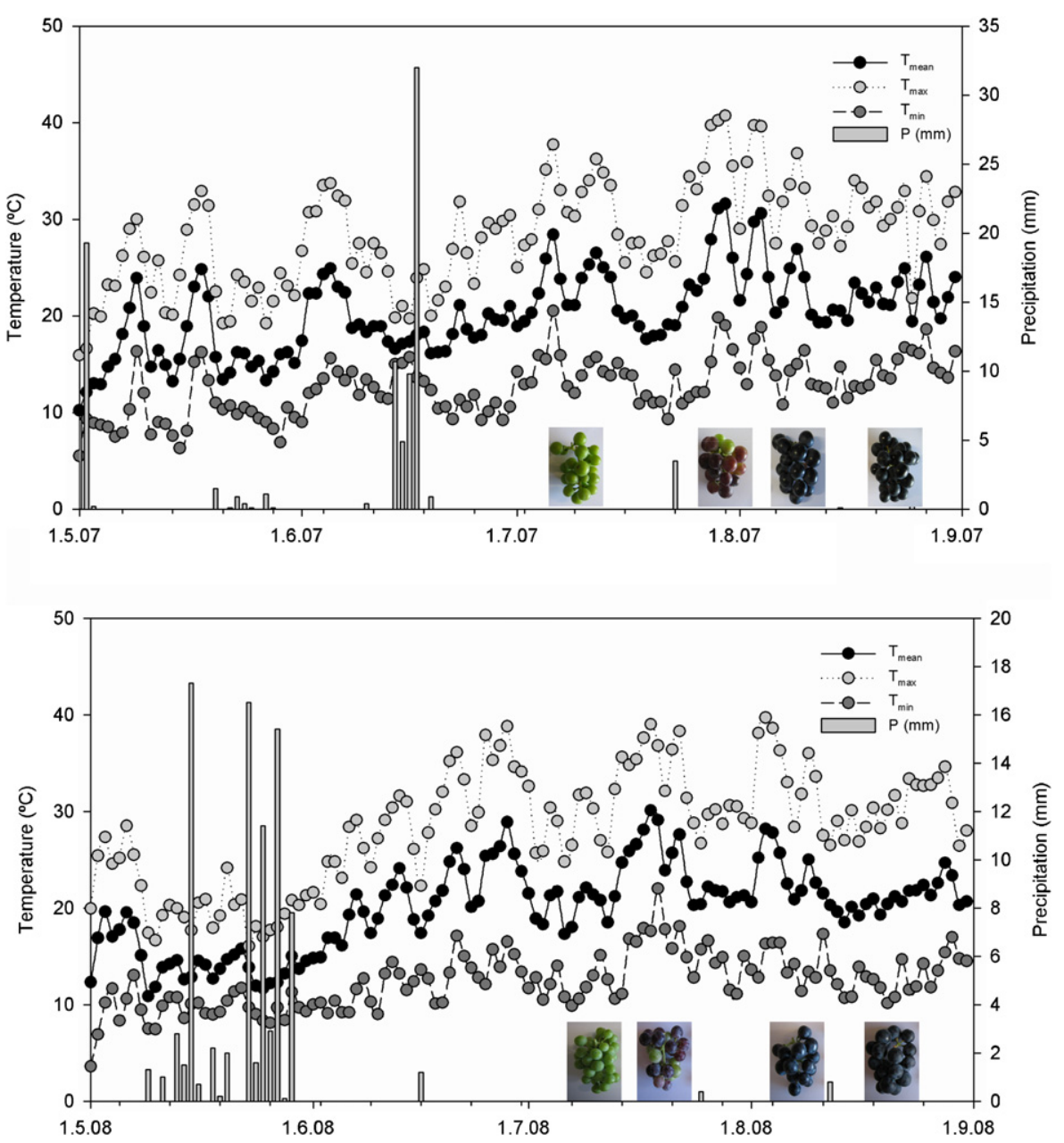

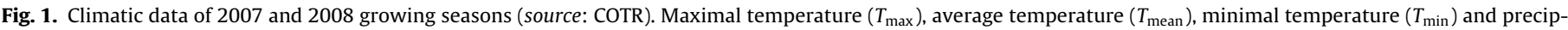

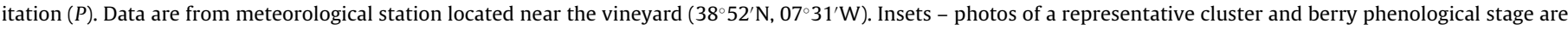
shown above.

vineyard from both sides of the vine. A sub-sample of 20 bunches was taken and was stored at $4{ }^{\circ} \mathrm{C}$. One hundred berries were weighed to determine berry weight and the juice extracted to determine total soluble solids (TSS, ${ }^{\circ}$ Brix) and titratable acidity (TA, $\mathrm{g}$ tartaric acid/L). The concentration of TSS was measured using a manual refractometer (ITREF 32, Instrutemp). The TA was assessed according to Office International de la Vigne et du Vin (OIV, 1990) procedure. For the determination of the berry fresh weight, 100 representative berries were selected and weighted. The second subsample was immediately frozen in liquid nitrogen from which four sub-samples of 10 frozen berries were carefully selected, peeled and the seeds removed. Skins were removed, weighted and ground in liquid nitrogen to a fine powder and stored at $-80^{\circ} \mathrm{C}$ until analysis.

\subsection{Total phenols analysis}

Total phenols extraction from berry skins was performed according to Boss et al. (1996). Briefly, $1 \mathrm{~mL}$ of methanol was added to $500 \mathrm{mg}$ of the ground tissue, lifted overnight at $-20^{\circ} \mathrm{C}$, centrifuged at $4{ }^{\circ} \mathrm{C}$ during $15 \mathrm{~min}$ at $16,100 \times \mathrm{g}$. The supernatant was removed and two additional extractions during $60 \mathrm{~min} / \mathrm{each}$ were made. The three supernatant were mixed and filtered through $0.45 \mu \mathrm{m}$ Whatman filters. Total phenol was quantified by the Folin Ciocalteau method (Singleton and Rossi, 1965) with modifications. In brief, to each microplate well, water $(235 \mu \mathrm{L})$, sample $(5 \mu \mathrm{L})$,
Folin-Ciocalteau's reagent $(15 \mu \mathrm{L})$ and saturated $\mathrm{Na}_{2} \mathrm{CO}_{3}$ aqueous solution $(45 \mu \mathrm{L})$ were added. The microplate was then incubated at $40^{\circ} \mathrm{C}$ for $30 \mathrm{~min}$ and the absorbance at $765 \mathrm{~nm}$ measured. Gallic acid was used as the standard and the results were expressed in $\mathrm{mg}$ of gallic acid equivalents per gram of fresh weight.

\subsection{Flavonoids and hormones extraction procedure}

Flavonoids and hormones extraction from berry skins was performed in acidified methanol. Briefly, $600 \mu \mathrm{L}$ of acidified methanol (1\%) was added to $100 \mathrm{mg}$ of the ground tissue, mixed 10 min at $4{ }^{\circ} \mathrm{C}$ and centrifuged at $4{ }^{\circ} \mathrm{C}$ during $15 \mathrm{~min}$ at $16,100 \times \mathrm{g}$. The supernatant was removed and one additional extraction was made. Both supernatants were collected and stored at $-80^{\circ} \mathrm{C}$ till analysis. Before analysis supernatants were filtered throughout a $0.22 \mu \mathrm{m}$ polytetrafluoethylene (PFTE) filter (Waters, Milford, MA, USA).

\subsection{Determination of flavonoid compounds}

Flavonoids analysis from berry skins was performed as described in Brossa et al. (2009) with modifications. Briefly, $10 \mu \mathrm{L}$ of each filtered extract was injected into the LC system (Acquity UPLC, Waters, Milford, MA, USA), where the chromatographic separation was carried out in a C18 column $(3.5 \mu \mathrm{m}$; $100 \times 2.1$ Waters, Milford, MA, USA) heated to $42{ }^{\circ} \mathrm{C}$ and using a $0.3 \mathrm{~mL} / \mathrm{min}$ flow. For detection and quantification ESI was set in 
positive mode (UPLC-(ESI+)-MS/MS) for anthocyanin and in negative mode (UPLC-(ESI-)-MS/MS) for all other flavonoids. Spectra were recorded from 100 to $900 \mathrm{amu} / \mathrm{z}$ and UV/vis detection confirmed at 365 for flavonols and $520 \mathrm{~nm}$ for anthocyanins.

Flavonols, proanthocyanidins and anthocyanins were determined by comparison and calibration with external standards of Rutin (Quercetin-rutinoside), Quercetin (Quercetin-rhamnoside), Isoquercitin (Quercetin glucoside) and Cyanidin-3-O-glucoside purchased from Sigma-Aldrich Fluka (Madrid, Spain); and malvidin-3-O-glucoside (Oenin), Isorhamnetin glucoside and Procyanidin B1 purchased from Extrasynthese (Genay, France).

\subsection{Determination of $A B A$ and $J A$}

Concentrations of ABA and JA in berry skin were simultaneously analysed by HPLC MS/MS as described by Brossa et al. (2011). For the analysis $5 \mu \mathrm{L}$ of each filtered extract was injected into the LC system (Acquity UPLC, Waters, Milford, MA, USA), using a XBridge C18 column ( $3.5 \mu \mathrm{m} ; 100 \times 2.1$ Waters, Milford, MA, USA). The MS/MS quantification was performed on an API 3000 triple quadrupole mass spectrometer (AB Sciex, Danaher Corp., Washington, DC) using multiple reaction monitoring (MRM) acquisition with the corresponding transitions for each analyte.

\subsection{ORAC and HORAC analysis}

Antioxidant capacity was measured in phenolic extracts (see total phenols analysis section) by the oxygen radical absorbance capacity (ORAC) assay using a method based on the ability of different substances to inhibit the oxidation of disodium fluorescein, a fluorescent protein, by the peroxyl radical generator, 2',2'-Azobis(2-amidinopropane)dihydrochloride (AAPH) (Cao et al., 1993). ORAC values were calculated from the loss of fluorescence from fluorescein at different incubation time points, relative to a Trolox standard solution in similar experimental conditions and expressed as Trolox Equivalents Antioxidant Capacity (TEAC). Antioxidant capacity was also measured by the Hydroxyl Radical Averting Capacity (HORAC) assay (Ou et al., 2002), which quantifies the quenching capability against hydroxyl radical. The HORAC assay is based on the oxidation of fluorescein by hydroxyl radicals and is expressed as micromol of caffeic acid (CAE) equivalent.

\subsection{Data analysis}

For all parameters four biological replicates were considered. Results were examined by analysis of variance (ANOVA) each season separately with SPSS software package 12.0 for Windows (SPSS Inc., Chicago, USA). When the $F$ test was significant, means were separated by Duncan's multiple range test $(p \leq 0.05)$. Principal component analysis (PCA) followed by between groups analysis (BGA) was performed with all studied skin variables. The R software (version 2.13.1, R Development Core Team, 2011) and the ade4 package were used (Culhane et al., 2002; Chessel et al., 2004; Thioulouse and Dray, 2009) and groups were defined as NI, RDI and DI.

\section{Results}

\subsection{Vine water status}

Irrigation influenced plant water status as shown by the pattern of predawn leaf water potential ( $\left.\Psi_{\text {pd }}\right)$ in both years (Fig. 2). Values of $\Psi_{\text {pd }}$ during pea size, véraison and maturation stages were significantly lower in NI vines than in RDI and NI ones in 2007. In turn, in 2008, NI and RDI showed the lower $\Psi_{\text {pd }}$ at pea size until maturation stage as compared with DI vines. In general, leaf water potential in DI and RDI treatments decreased slightly from the beginning of the irrigation to reach more negative values at full maturation stage in both seasons. In NI vines, $\Psi_{\text {pd }}$ decreased from pea size stage onwards, reaching mean values of $-0.5 \mathrm{MPa}$ at full maturation in 2007 and $-0.7 \mathrm{MPa}$ in 2008 (Fig. 2). The values were in general lower in 2008 as compared to 2007.

\subsection{Fruit characteristics}

As it is shown in Fig. 3a, DI and RDI treatments induced the highest berry fresh weight in 2007. In 2008, berry growth was in general higher in DI and NI than in RDI. Berry fresh weight was significantly higher in 2007 than in 2008. Skin to pulp ratio was higher in NI treatment as compared with RDI and DI in 2007. However in 2008, no significant differences were found at full maturation stage, albeit RDI and NI showed a greater ratio along the other phenological stages (Fig. 3b).

As it is shown in Fig. 4a, during 2007 year no differences in sugar accumulation were found among water regime treatments. Similarly, no differences in sugar/acidity ratio between treatments in all of the phenological stages were observed (Fig. 4b). Nonetheless, during 2008 year, RDI vines showed a delay in sugar accumulation from véraison onwards. At full maturation, the sugar/acidity ratio was higher in NI vines as compared with DI and RDI ones (Fig. 4c).

\subsection{Grape skin composition}

As shown in Fig. 5 total anthocyanin, total proanthocyanidin and ABA concentration were significantly different when comparing treatments and years. Total anthocyanin starts to accumulate from véraison onwards in all treatments being significantly higher in NI vines as compared to RDI and DI ones in 2008 (Fig. 5a). Surprisingly, at full maturation total anthocyanin concentration was lower in NI vines as compared to RDI and DI ones during both years (Fig. 5a). The highest anthocyanin concentration at full maturation was observed in RDI in 2007 and in DI in 2008. Proanthocyanidins accumulation trend showed a decline from pea size stage until full maturation stage in both years (Fig. 5b), with the exception of an accumulation peak in $2008 \mathrm{NI}$ at véraison stage. In both years DI treatment induced a greater concentration of skin total proanthocyanidins as compared with both RDI and NI treatments (Fig. 5b) at full maturation. The accumulation of ABA in grape skins increased early in berry development and transiently. In all irrigation treatments, ABA maximum concentration was observed at véraison during 2007 year and at mid-ripening stage during 2008 year (Fig. 5c). Differences between treatments in ABA concentration were observed in véraison and MR stages in 2007, being much higher in NI vines than in RDI and DI ones. In 2008, significant differences were observed since pea size, being highest in DI vines. At full maturation, in both growing years NI treatments showed a higher ABA concentration than RDI and DI, albeit these differences were statistically significant only in 2008 .

The accumulation trend of total phenols, total flavonols and jasmonic acid and the antioxidant activity is presented in Table 1. In general, total phenol content of the skin was higher in RDI and NI vines when it was compared to DI during the two consecutive years. Regardless of the treatment, an inter-annual variability in total phenol concentration was observed, being much higher in 2008 than in 2007. Total flavonols accumulation appears to be water supply dependent. In fact, its concentration was higher in skin berries belonging to irrigated vines (DI and RDI) than to nonirrigated ones. During the first year of the experiment, 2007, total flavonols concentration was highest in DI skins at all phenological stages except at véraison. During the second year, it was highest in DI and RDI skins along all phenological stages and in particular at full maturation stage. 


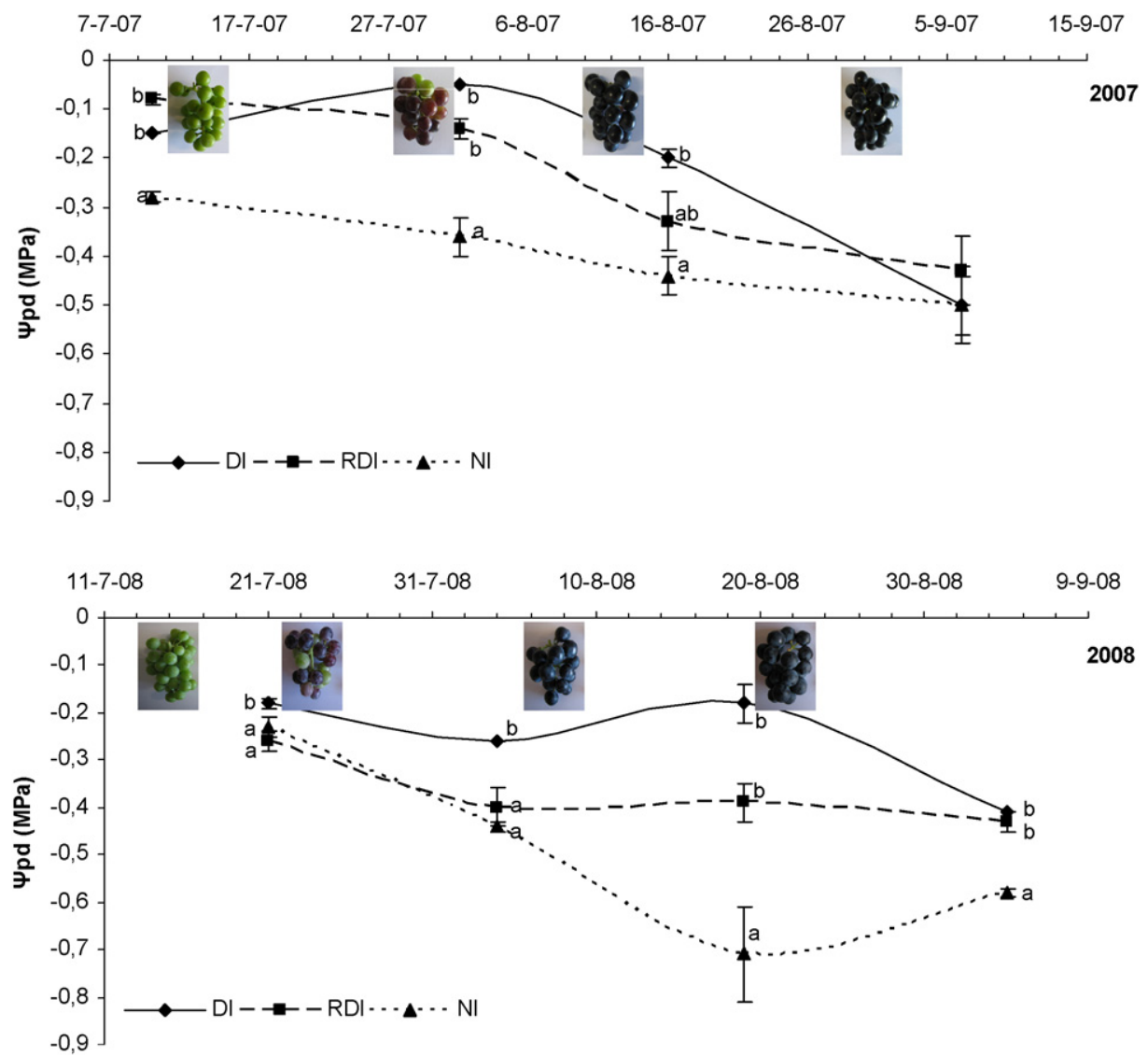

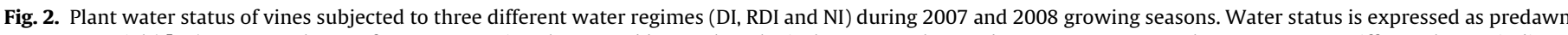

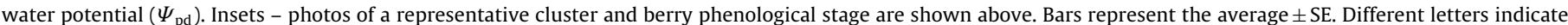
significant differences between treatments at the same date using Duncan test $(p \leq 0.05)$.

Table 1

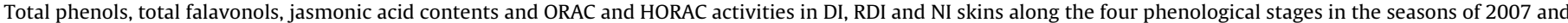
2008 .

\begin{tabular}{|c|c|c|c|c|c|c|c|c|}
\hline & \multicolumn{4}{|l|}{2007 season } & \multicolumn{4}{|l|}{2008 season } \\
\hline & Pea size & Véraison & Maturation & Full maturation & Pea size & Véraison & Maturation & Full maturation \\
\hline \multicolumn{9}{|c|}{ Total phenols (mg GAE/g FW) } \\
\hline FI & $31.8 \pm 0.7^{\mathrm{a}}$ & $43.30 \pm 2.7^{a}$ & $62.22 \pm 15.9^{a}$ & $33.60 \pm 1.3^{\mathrm{a}}$ & $47.68 \pm 2.70^{\mathrm{a}}$ & $50.78 \pm 3.62^{\mathrm{a}}$ & $47.66 \pm 3.32^{\mathrm{a}}$ & $40.12 \pm 2.37^{a}$ \\
\hline RDI & $39.1 \pm 3.5^{\mathrm{ab}}$ & $45.80 \pm 2.5^{\mathrm{a}}$ & $30.28 \pm 0.7^{\mathrm{a}}$ & $34.44 \pm 5.7^{\mathrm{a}}$ & $48.64 \pm 8.17^{\mathrm{a}}$ & $50.75 \pm 4.65^{\mathrm{a}}$ & $53.85 \pm 2.02^{\mathrm{a}}$ & $63.70 \pm 9.13^{b}$ \\
\hline $\mathrm{NI}$ & $41.9 \pm 1.7^{\mathrm{b}}$ & $44.60 \pm 1.5^{\mathrm{a}}$ & $50.99 \pm 8.0^{\mathrm{a}}$ & $42.51 \pm 4.6^{\mathrm{a}}$ & $40.82 \pm 5.72^{\mathrm{a}}$ & $66.82 \pm 8.82^{\mathrm{a}}$ & $53.06 \pm 4.21^{\mathrm{a}}$ & $47.09 \pm 4.47^{a b}$ \\
\hline \multicolumn{9}{|c|}{ Total flavonols ( $\mu \mathrm{g} / \mathrm{g}$ FW) } \\
\hline FI & $299.2 \pm 46.2^{\mathrm{b}}$ & $42.73 \pm 2.2^{\mathrm{a}}$ & $74.61 \pm 2.2^{\mathrm{b}}$ & $73.28 \pm 2.8^{\mathrm{b}}$ & $38.56 \pm 1.74^{\mathrm{c}}$ & $35.79 \pm 0.49^{\mathrm{a}}$ & $86.79 \pm 9.72^{b}$ & $46.24 \pm 1.25^{\mathrm{b}}$ \\
\hline RDI & $115.4 \pm 11.3^{\mathrm{a}}$ & $39.32 \pm 2.0^{\mathrm{a}}$ & $31.95 \pm 1.1^{\mathrm{a}}$ & $50.26 \pm 2.2^{\mathrm{a}}$ & $22.59 \pm 0.54^{\mathrm{a}}$ & $36.75 \pm 1.29^{a}$ & $37.44 \pm 1.81^{\mathrm{a}}$ & $45.65 \pm 1.37^{b}$ \\
\hline $\mathrm{NI}$ & $87.8 \pm 8.7^{\mathrm{a}}$ & $104.49 \pm 1.7^{b}$ & $29.82 \pm 1.5^{a}$ & $54.55 \pm 2.6^{a}$ & $28.65 \pm 0.78^{b}$ & $105.38 \pm 22.72^{b}$ & $42.02 \pm 1.47^{a}$ & $34.89 \pm 1.37^{a}$ \\
\hline \multicolumn{9}{|c|}{ Jasmonic acid (nmol/g FW) } \\
\hline $\mathrm{FI}$ & $0.45 \pm 0.03^{a}$ & $0.49 \pm 0.03^{\mathrm{a}}$ & $0.47 \pm 0.03^{\mathrm{a}}$ & $0.45 \pm 0.02^{\mathrm{a}}$ & $0.52 \pm 0.08^{\mathrm{a}}$ & $0.39 \pm 0.01^{\mathrm{a}}$ & $0.39 \pm 0.01^{\mathrm{a}}$ & $0.41 \pm 0.01^{\mathrm{a}}$ \\
\hline RDI & $0.49 \pm 0.08^{a}$ & $0.49 \pm 0.03^{\mathrm{a}}$ & $0.50 \pm 0.06^{\mathrm{a}}$ & $0.44 \pm 0.03^{a}$ & $0.40 \pm 0.01^{\mathrm{a}}$ & $0.41 \pm 0.01^{\mathrm{a}}$ & $0.40 \pm 0.01^{\mathrm{a}}$ & $0.42 \pm 0.02^{\mathrm{a}}$ \\
\hline NI & $0.60 \pm 0.10^{\mathrm{a}}$ & $0.59 \pm 0.07^{\mathrm{a}}$ & $0.50 \pm 0.04^{\mathrm{a}}$ & $0.46 \pm 0.01^{\mathrm{a}}$ & $0.39 \pm 0.01^{\mathrm{a}}$ & $0.42 \pm 0.01^{\mathrm{a}}$ & $0.40 \pm 0.01^{\mathrm{a}}$ & $0.41 \pm 0.00^{\mathrm{a}}$ \\
\hline \multicolumn{9}{|c|}{ ORAC ( $\mu$ mol TEAC/g FW) } \\
\hline FI & $104.7 \pm 2.6^{a}$ & $77.18 \pm 5.7^{\mathrm{a}}$ & $101.26 \pm 16.3^{\mathrm{a}}$ & $105.91 \pm 8.6^{\mathrm{a}}$ & $392.13 \pm 18.77^{a}$ & $391.16 \pm 8.53^{\mathrm{a}}$ & $392.31 \pm 43.61^{\mathrm{a}}$ & $403.60 \pm 55.71^{a}$ \\
\hline RDI & $100.2 \pm 1.7^{\mathrm{a}}$ & $77.38 \pm 4.7^{\mathrm{a}}$ & $103.10 \pm 4.6^{\mathrm{a}}$ & $115.31 \pm 2.8^{\mathrm{a}}$ & $382.14 \pm 14.60^{\mathrm{a}}$ & $360.93 \pm 28.00^{\mathrm{a}}$ & $474.00 \pm 87.41^{\mathrm{a}}$ & $416.01 \pm 85.70^{\mathrm{a}}$ \\
\hline NI & $99.2 \pm 7.0^{\mathrm{a}}$ & $87.77 \pm 3.4^{a}$ & $102.62 \pm 3.8^{a}$ & $104.53 \pm 3.0^{\mathrm{a}}$ & $379.04 \pm 20.84^{a}$ & $387.75 \pm 8.14^{\mathrm{a}}$ & $390.83 \pm 12.30^{a}$ & $416.15 \pm 48.54^{a}$ \\
\hline \multicolumn{9}{|c|}{ HORAC ( $\mu$ mol CAE/skin) } \\
\hline FI & $157.94 \pm 24.6^{\mathrm{a}}$ & $167.17 \pm 12.3^{\mathrm{a}}$ & $146.79 \pm 27.5^{\mathrm{a}}$ & $164.95 \pm 26.4^{\mathrm{a}}$ & $534.34 \pm 34.72^{\mathrm{a}}$ & $364.61 \pm 5.91^{\mathrm{a}}$ & $366.10 \pm 35.85^{b}$ & $334.35 \pm 15.57^{\mathrm{a}}$ \\
\hline RDI & $213.62 \pm 18.4^{\mathrm{a}}$ & $175.41 \pm 15.5^{\mathrm{a}}$ & $164.06 \pm 20.5^{\mathrm{a}}$ & $190.55 \pm 28.1^{\mathrm{a}}$ & $376.23 \pm 57.42^{\mathrm{a}}$ & $360.41 \pm 25.72^{\mathrm{a}}$ & $257.53 \pm 37.89^{a}$ & $292.94 \pm 39.42^{a}$ \\
\hline $\mathrm{NI}$ & $210.27 \pm 8.6^{a}$ & $176.59 \pm 17.7^{\mathrm{a}}$ & $156.16 \pm 21.7^{\mathrm{a}}$ & $216.48 \pm 32.0^{\mathrm{a}}$ & $417.63 \pm 37.93^{a}$ & $360.47 \pm 42.12^{\mathrm{a}}$ & $278.55 \pm 19.48^{\mathrm{ab}}$ & $235.14 \pm 32.79^{a}$ \\
\hline
\end{tabular}

Values are means $\pm \mathrm{SE}(n=4)$.

Values followed by the different letters are significantly different (Duncan $p \leq 0.05$ ). 

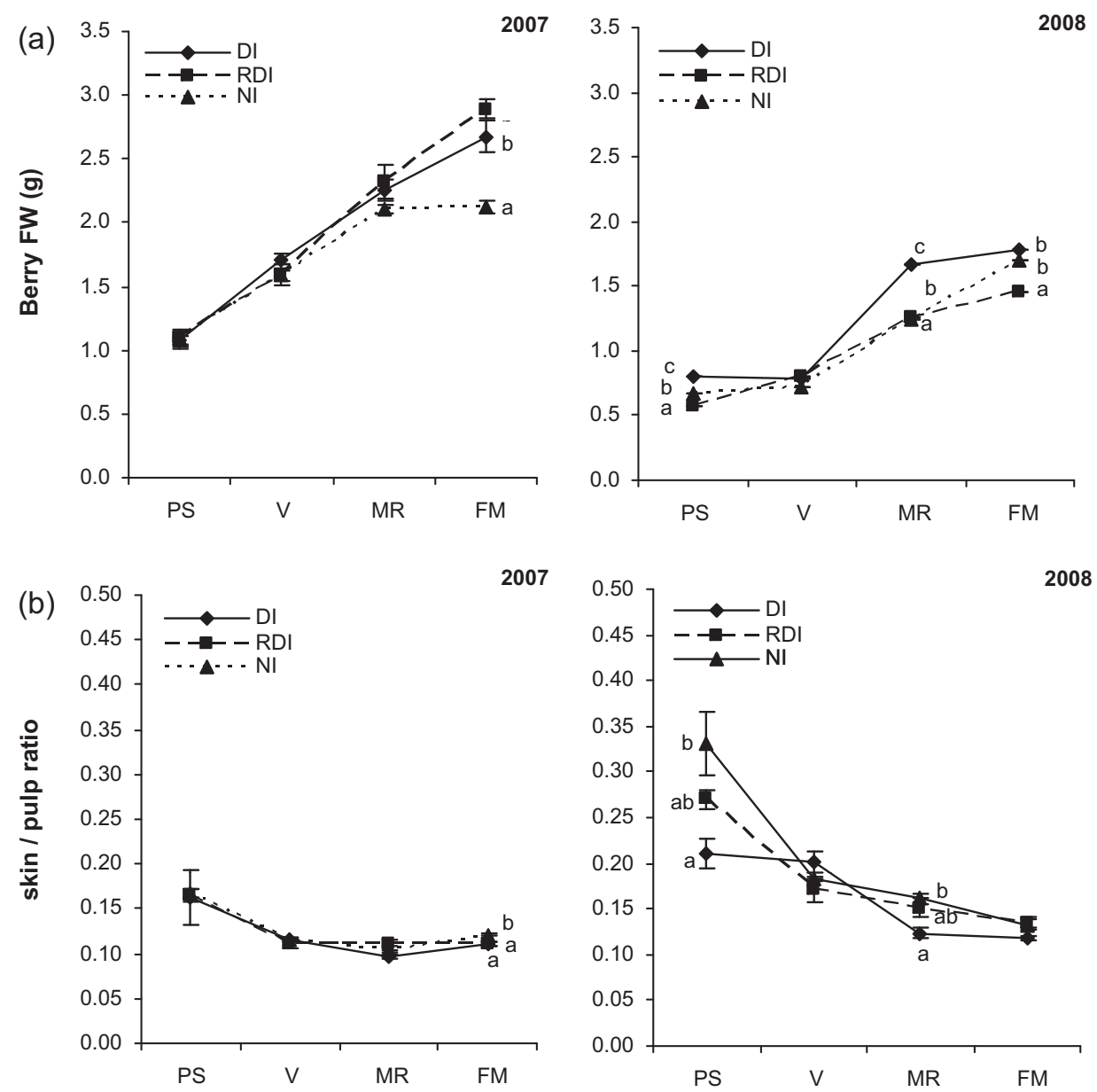

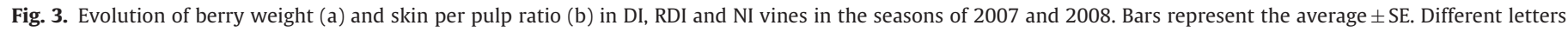
indicate significant differences between treatments at the same date using Duncan test $(p \leq 0.05)$.

Two complementary tests were performed to evaluate the antioxidant activities (ORAC and HORAC). Results demonstrate that in general RDI induced a slight, but not significant, increase of ORAC activity in berry skin. No differences were observed in skin HORAC activity among the different treatments (Table 1 ). Nevertheless, significant differences were found between years in both, with ORAC and HORAC antioxidant capacity values being higher in 2008 than in 2007.

\subsection{PCA analysis}

Principal component analysis followed by between groups analysis (PCA-BGA) was used to found patterns in the data in order to classify any combination of variables that could explain the effects of the irrigation treatments on berry quality parameters. PCA which included all variables concerning berry composition at the different phenological stages during both years was performed to graphically illustrate the overall behaviour of the studied grapevines (Fig. 6a). The first component obtained from PCA in each stage accounted for $47 \%, 32 \%, 31 \%$ and $29 \%$ of the total variance observed within the whole data set at pea size, véraison, maturation and full maturation stages, respectively. The second component accounted for $18 \%, 16 \%, 22 \%$ and $24 \%$ at pea size, véraison, maturation and full maturation stages, respectively. The analysis between groups, after PCA, showed that at the first and second principal component, a separation between the different irrigation treatments occurs (Fig. 6b). In all phenological stages, except véraison and in the 2 years, DI was separated at the first component from RDI and NI irrigations, and RDI and NI were separated at the second component. At véraison stage, NI was separated from RDI and DI at the first component, and at the second component, RDI and DI were, then, separated. BGA-PCA was performed to graphically illustrate the overall behaviour of the studied grapevines (Fig. 6a).

Fig. 6b showed the variables that contribute the most to the spread along component 1 and component 2 . The recurrent parameters explaining the separation of DI treatment in both years in all phenological stages, except véraison, are total proanthocyanidins and total flavonols. In fact, the concentration of these parameters was enhanced by DI treatment. However, at véraison stage, these parameters jointly with all the other studied parameters explained the separation of NI treatment.

\section{Discussion}

Due to the occurrence of severe drought periods, drip irrigation began to be spread in Mediterranean traditional vineyard in order to maintain yield and stabilise wine quality from year to year. With the present investigation we tried to understand the impact of different water deficit regimes applied in field conditions on the ripening process and quality of berries of one of the most cultivated grapevine varieties in Iberian Peninsula. The two successive years of the experiment were contrasting in what concerns the vine water status, being more evident the incidence of some water deficit in 2008 than in 2007. Nevertheless, temperature was higher in 2007 than in 2008 (Fig. 1). The principal component analysis followed by between groups analysis (PCA-BGA) including all parameters 

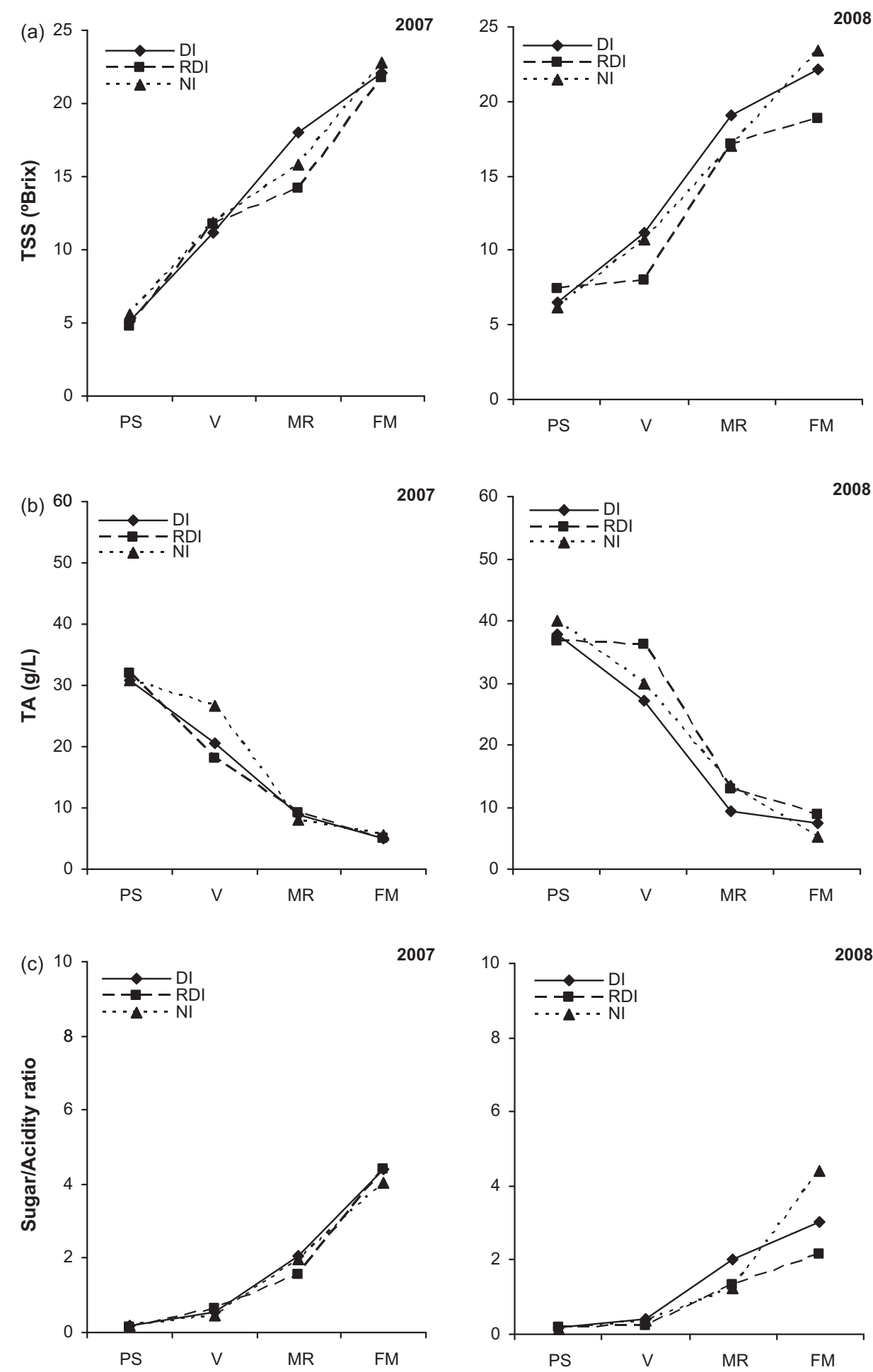

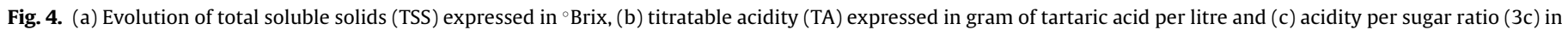
DI, RDI and NI vines along the four phenological stages in the seasons of 2007 and 2008 . Values are mean of 100 berries.

of both years, showed a consistent separation of the different irrigation treatments at the first and at the second component. At all phenological stages, except véraison, DI treatment was separated from the RDI and NI ones. It is also important to note that the separation occurs already at pea size stage even when NI and RDI treatments did not show large differences between them and DI treatment in what concerns vine water status. This seems to suggest a cumulative effect of the previous water stress year(s) on NI and RDI grapevines since the observed separations were detected already at early reproductive stages. Although PCA-BGA allows to separate the irrigation treatments, it was hard to understand which parameters contribute to this separation using the between group analysis statistical tool. In fact, the only recurrent parameters that may explain DI separation at all phenological stages were total proanthocyanidins and total flavonols, which were in fact enhanced by DI regime in both years. All other studied parameters changed 

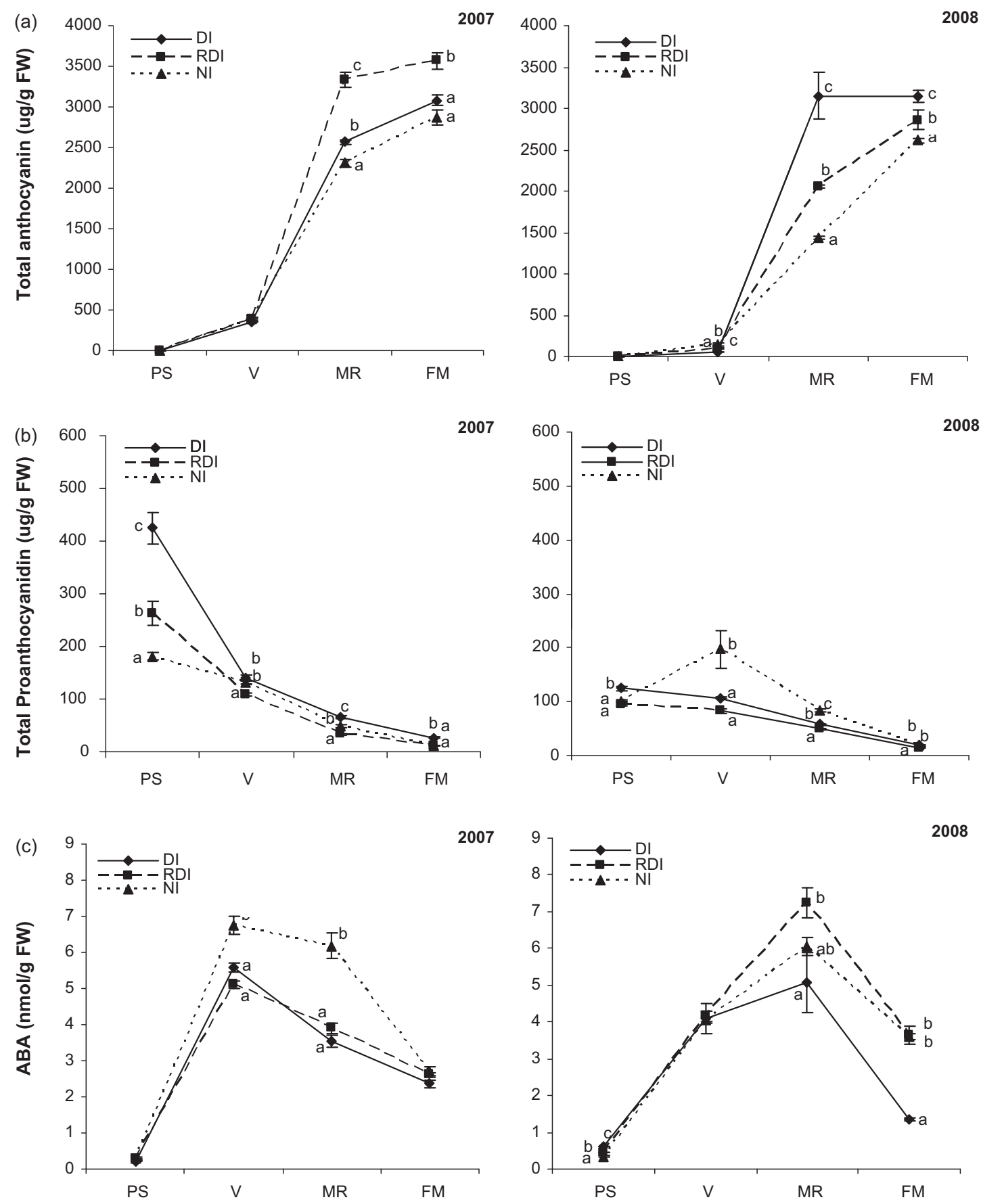

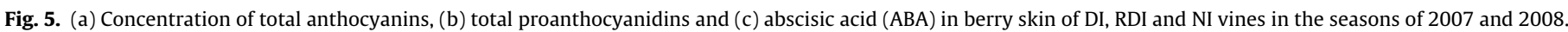
Bars represent the average \pm SE. Different letters indicate significant differences between treatments at the same date using Duncan test ( $p \leq 0.05$ ).

their influence to the separation among stages and from year to year and no reliable trend was found to indicate the existence of a dominant influence of seasonal climate on berry development and composition, as it was previously reported (Shellie, 2011). Moreover, these results showed that PCA-BGA is a valuable tool to determine the irrigation effects in field experiments where several factors either than irrigation could be responsible for differences in the accumulation of secondary compounds and hormones.

Due to rainy springs, non-irrigated grapevine (NI) did not suffer from severe water stress in both years and in RDI and DI vines experienced only mild stress. This is supported by small or absent differences in grape berry fresh weight between the treatments as well as in the skin to pulp ratio, as it was reported by other authors (Ojeda et al., 2002; Kennedy et al., 2002; Acevedo-Opazo et al., 2010; Santesteban et al., 2011). Differences observed in RDI, concerning the rate of accumulation of TSS and the acidity breakdown in berry during 2008 year, may suggest that the ripening process of RDI berries was delayed in comparison with DI and NI ones. Indeed, RDI berries reached their peak of ABA concentration only at maturation stage, which may support the observed delay of ripening in RDI berries since the dramatic increase of ABA concentration was already related to the onset of ripening by different authors (Davies et al., 1997; Deluc et al., 2009; Owen et al., 2009; Wheeler et al., 2009). During 2008 it was also visually observed in the field a delay in the onset of ripening in RDI clusters in comparison with NI and DI vines. No clear explanation to this delay was 


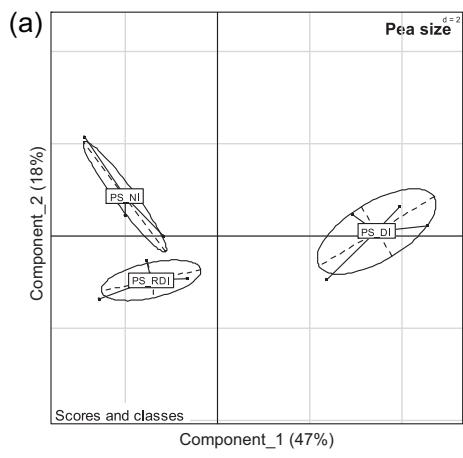

(b)

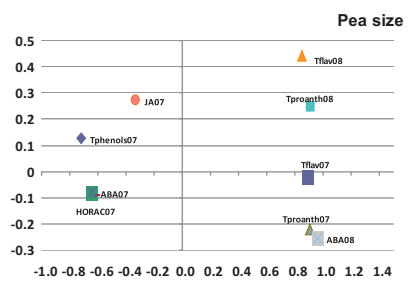

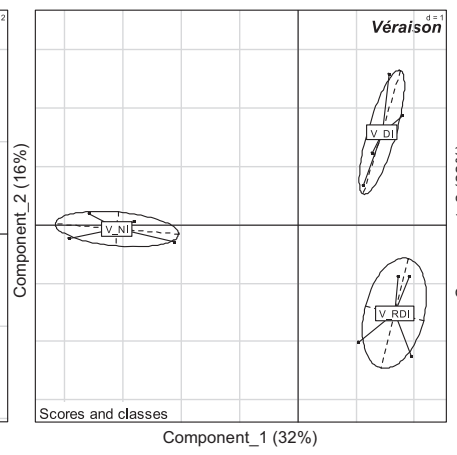

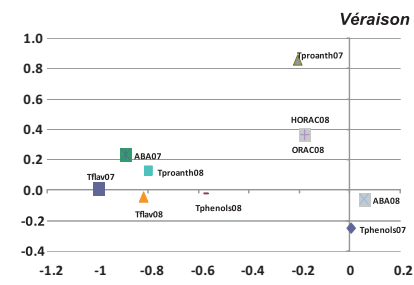

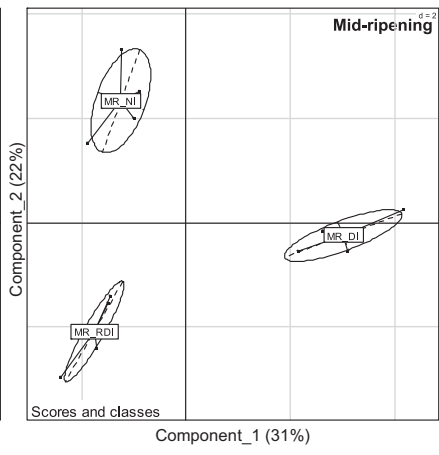
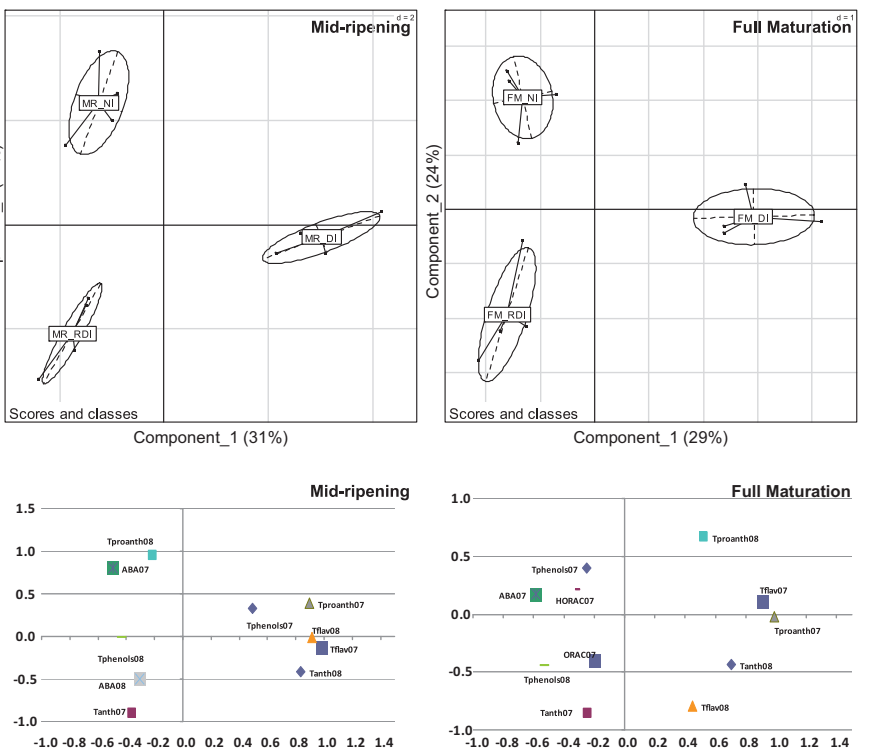

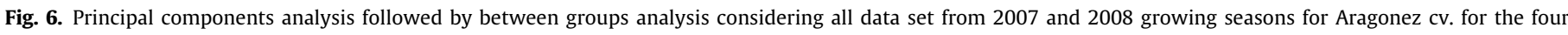

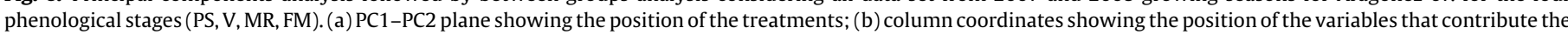

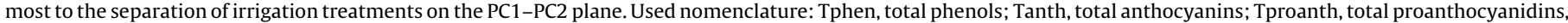
Tflav, total flavonols; JA, jasmonic acid; ABA, abscisic acid; 07 corresponds to 2007 season and 08 corresponds to 2008 season.

found, but 2008 was characterised by a rainy spring which could have influenced flowering or fruit set time in these vines.

During both growing years and particularly during 2008, total anthocyanin content was surprisingly low in non irrigated vines contrasting thereby with different reports (Esteban et al., 2001; Chaves et al., 2007; Santesteban et al., 2011). Anthocyanins accumulation is environment dependent. Its degradation and/or the inhibition of its synthesis was reported particularly when the clusters were exposed to high sunlight radiation (Spayd et al., 2002) or/and high temperature (Spayd et al., 2002; Mori et al., 2007; Tarara et al., 2008) what could be the situation in the present study. It is clear that anthocyanin accumulation slowed in NI after véraison in both years (Fig. 4a). As no differences were found in skin to pulp ratio between treatments, it could be suggested that differences in anthocyanin concentration are due to modulation in its biosynthetic pathway. Indeed, our investigation showed that the expression of genes responsible for anthocyanin synthesis namely UFGT supports this hypothesis (data not shown). Reports by Girona et al. (2009) showed that the imposition of water stress early in the year (stage II of berry growth) reduced berry quality parameters namely anthocyanin accumulation. Since in the present study, only a mild stress was observed in NI vines at the beginning of the experiment, the presence of a second factor responsible for such decline in anthocyanin concentration in NI berries may be suggested. Recently, Tarara et al. (2008) observed that clusters subjected to temperature above $35^{\circ} \mathrm{C}$ for an average of $89 \mathrm{~h}$ during ripening, had low total anthocyanin concentration, low concentration of all individual anthocyanins and high concentration of acylated forms of anthocyanins (namely malvidin-3-coumaryl-glucoside and malvidin 3-acetyl-glucoside). In the present experiment, it was observed that NI vines precociously lost their basal leaves implying a direct exposition of clusters to sunlight radiation incidence and to a consequent heating. In addition the meteorological data (supplementary data) shows that each sampling date was preceded by at least three consecutive days of high temperature (with the maximum temperature above $35^{\circ} \mathrm{C}$ ). Furthermore, data on anthocyanin profile showed an increase in acylated forms (data not shown) during both years. Altogether, the effect of high temperatures on the biosynthesis of anthocyanin in NI vines might be responsible for the observed effects on such parameter.

Flavonols are important berry quality components since they can conjugate anthocyanin, which stabilises the colour of young wines (Boulton, 2001). The impact of water availability conditions on grape flavonols is controversial since they were reported to be moderately affected by deficit irrigation (Grimplet et al., 2007) or not affected by water stress (Kennedy et al., 2002). More recently, Deluc et al. (2009) working with two different varieties showed that in a white grapevine ('Chardonnay'), flavonols concentration increased under water deficits, while in the red grapevine ('Cabernet Sauvignon') no differences were observed. In the present study, flavonols content reached a peak at véraison only in NI vines during both years, contrasting with other reports where a peak of accumulation few weeks after véraison was observed (Downey et al., 2003). In RDI and DI vines, the peak of accumulation was observed at pea size stage in 2007 year while in 2008 no peak was observed. Contrasting with previous reports, total flavonols accumulation was enhanced by irrigation in comparison to non irrigated vines. This suggests that water availability has a positive effect on the accumulation and biosynthesis of flavonols. Indeed, the between group analysis after PCA-BGA showed that flavonols concentration is positively related with DI irrigation at all phenological stages except at véraison. Nonetheless, these results may be magnified since other environmental factor(s) are probably obstructing the accumulation of flavonoids in NI vines. Since anthocyanins and flavonols share the same biosynthetic enzymes (Mattivi et al., 2006) it can be suggested that the same factor that inhibited and/or degraded anthocyanins is affecting the flavonol accumulation.

Proanthocyanidins are important sensory components and the alterations (namely polymerisation) that occur during grape development are complex (Kennedy et al., 2002). Total proanthocyanidins concentration was reported to decrease during berry development in other studies (Downey et al., 2003; Gagné et al., 2006). This apparent loss in proanthocyanidins concentration throughout ripening is in fact the result of losses in extraction due to interactions with other polymers (Kennedy et al., 2001; Downey et al., 2003) or/and to oxidation (Kennedy et al., 2000; Bindon and 
Kennedy, 2011). Previous reports showed that proanthocyanidins were only slightly affected by water deficit (Downey et al., 2006; Castellarin et al., 2007b) and the increases in skin tannins that accompany water deficits appear to result more from differential growth sensitivity of the inner mesocarp and the exocarp than from direct effects on phenolic biosynthesis (Roby et al., 2004). In the present investigation, it was observed that total proanthocyanidins were higher at full maturation stage in the continuously irrigated vines (DI) than in RDI and NI ones. However, it is not possible to confirm if this increase is due to an enhancement of proanthocyanidin biosynthesis. More recently, Lacampagne et al. (2010) showed that ABA application affects proanthocyanidin content by reducing the activity of enzymes which are responsible for its synthesis (LAR and ANR) and repressing the expression of genes (LAR1, LAR2 and ANR). Interestingly, this may be taken into account to explain the inhibition of the biosynthesis of proanthocyanidins in NI vines, since endogenous ABA was statistically higher in berries of RDI and NI in both years. In addition, an inter-annual variation in proanthocyanidins concentration was observed during berry development, being much high in 2007 than 2008, which suggests that other environmental cues (namely temperature and air dryness) may have a profound effect in the proanthocyanidin biosynthetic pathways.

When comparing véraison with all the other stages, it seems to have a different behaviour. PCA-BGA showed that NI treatment discriminates from both other treatments (Fig. 6a), whereas in the other phenological stages DI discriminates from NI and RDI. In addition, all studied parameters explained this separation of NI at véraison (Fig. 6b). This may suggest an acceleration of the onset of ripening at NI stage berries in relation with RDI and DI. Before véraison, the berry is exclusively connected to the vine by the xylem and the water deficit impact directly on berry growth by changes in water import through the xylem. Berry ripening appears to be the consequence of reduced turgor pressure $(\mathrm{P})$ of berry pericarp cells (see review by Tyerman et al., 2012) and pre-véraison water stress may decreases berry cell turgor even more (Thomas et al., 2006), which may act as a signal to the onset of ripening (Matthews et al., 2009; Wada et al., 2009) probably by increasing sugar influx and ABA concentration (Castellarin et al., 2007b). In the present study, ABA concentration was highest in NI berries at véraison in 2007 but not in 2008. This supports the hypothesis of an advancement of ripening in NI vines at least in 2007 growing season, since ABA levels were reported to be transiently enhanced by water stress (Castellarin et al., 2007a). On the other hand, Owen et al. (2009) demonstrates that before the onset of veraison the ABA concentration declines because of its conjugation to ABA-glucose ester (ABA-GE). Altogether, this highlights the need of future research to study $A B A$ biosynthesis and regulation in grape berry under water deficits, which may improve our understanding on the role of this hormone in ripening and in fruit composition parameters in developing grape berries.

It is already reported that in grape berries JA concentration decreased by 30 days after flowering and remained low throughout ripening (Kondo and Fokuda, 2001). In the present study, JA concentration was constant during berry ripening, and no significant differences were observed among irrigation treatments. This suggests that JA is, at least at these studied phenological stages, not modulated by mild to moderate differences in the plant water status.

Large seasonal variations of total phenols concentration and of other flavonoids content were observed between the two consecutive years. This is consistent with previous studies (Esteban et al., 2001; Downey et al., 2004; Castellarin et al., 2007a) and suggests that an additional factor rather than water regime must be considered (e.g. climatic factors namely temperature) between the years.
In spite of the differences in phenolic and flavonoids concentrations that contribute to antioxidant activity observed between treatments, no differences were registered in what concerns the antioxidant activity in both years. These results suggest that other non-measured parameters either than phenolics (perhaps vitamins) are responsible for ORAC and HORAC activities, and that in our conditions, water deficits did not change the bioactive quality of grape berries.

\section{Conclusion}

It was, once more, demonstrated the advantage of deficit irrigation to maintain grape berry quality. At most sampling dates, concentrations of phenolics were observed to be higher in the skin of berries from vines with more water availability than in non irrigated ones even in years where water deficits is not pronounced as 2007 and even 2008. Indeed, it is important to note that even small differences were observed in plant water status; important variations were observed in grape berry quality compounds. Depending on the year, the best values of flavonoid compounds were observed in DI or RDI treatment, which suggested the impact of seasonal climate in the success of deficit irrigation regime. In fact, it is clear from the present study that climatic conditions and their interactions are important factors contributing to the ripening of grape berries. In fact, although only a mild to moderate stress was observed in NI vines during 2007 and 2008, a decrease in the quality parameters in grape skins as compared to DI and RDI, was probably due to the incidence of high temperature and excessive sunlight exposition that was observed. This highlights the crucial role of irrigation in maintaining the cluster microclimate within an optimum, since it affects the synthesis of several compounds relevant to wine quality. Besides, the rate of accumulation of different compounds during berry development was different among treatments.

Finally, we demonstrated that ABA was regulated by the intensity of water deficits and this was observed at early stages of berry development. However, this ABA response did not trigger other ripening-associated events such as sugar or anthocyanins accumulations showing that other mechanisms than hormonal are involved in the onset of ripening.

\section{Acknowledgements}

O. Zarrouk, R. Francisco, M. Pintó-Marijuan and J.M. Costa are supported by fellowships granted by Fundação para a Ciência e Tecnologia (FCT). PTDC/AGR-ALI/100636/2008 (FCT-Portugal) and BFU2009-08865 (Ministerio de Ciencia y Innovación - Spain) projects provided funds to support part of the research presented. Authors acknowledge also the Herdade Seis Reis (Estremoz, Portugal) for providing a large set of facilities.

\section{References}

Acevedo-Opazo, C., Ortega-Farias, S., Fuentes, S., 2010. Effects of grapevine (Vitis vinifera $\mathrm{L}$.) water status on water consumption, vegetative growth and grape quality: an irrigation scheduling application to achieve regulated deficit irrigation. Agricultural Water Management 97, 956-964.

Allen, R.G., Pereira, L.S., Raes, D., Smith, M., 1998. Crop evapotranspiration. Guidelines for computing crop water requirements. FAO Irrigation and Drainage Paper No. 56. Rome, Italy, pp. 15-27.

Bindon, K.A., Kennedy, J.A., 2011. Ripening-induced changes in grape skin proanthocyanidins modify their interaction with cell walls. Journal of Agriculture and Food Chemistry 59, 2696-2707.

Boss, P.K., Davies, C., Robinson, S.P., 1996. Analysis of the expression of anthocyanin pathway genes in developing Vitis vinifera L. cv Shiraz grape berries and the implications for pathway regulation. Plant Physiology 111, 1059-1066.

Boulton, R., 2001. The copigmentation of anthocyanins and its role in the color of red wine: a critical review. American Journal of Enology and Viticulture 52, 67-87. 
Bravdo, B., Hepner, Y., Loinger, C., Cohen, S., Tabacman, H., 1985. Effect of irrigation and crop level on growth, yield and wine quality of Cabernet Sauvignon. American Journal of Enology and Viticulture 36, 132-139.

Brossa, R., Casals, I., Pintó-Marijuan, M., Fleck, I., 2009. Leaf flavonoid content in Quercus ilex L. resprouts and its seasonal variation. Trees 23, 401-408.

Brossa, R., López-Carbonell, M., Jubany-Marí, T., Alegre, L., 2011. Interplay between abscisic acid and jasmonic acid and its role in water-oxidative stress in wildtype, ABA-deficient, JA-deficient, and ascorbate-deficient Arabidopsis plants. Journal of Plant Growth Regulation 30, 322-333.

Cao, G., Alessio, H.M., Cutler, R.G., 1993. Oxygen-radical absorbance capacity assay for antioxidants. Free Radical Biology and Medicine 14, 303-311.

Castellarin, S., Matthews, M.A., Gaspero, G.D., Gambetta, G.A., 2007a. Water deficits accelerate ripening and induce changes in gene expression regulating flavonoid biosynthesis in grape berries. Planta 227, 101-112.

Castellarin, S.D., Pfeiffer, A., Sivilotti, P., Degan, M., Peterlunger, E., DiGaspero, G., 2007b. Transcriptional regulation of anthocyanin biosynthesis in ripening fruit of grapevine under seasonal water deficit. Plant, Cell \& Environment 30, 1381-1399.

Chaves, M.M., Santos, T.P., Souza, C.R., Ortuño, M.F., Rodrigues, M.L., Lopes, C.M., Maroco, J.P., Pereira, J.S., 2007. Deficit irrigation in grapevine improves water use efficiency while controlling vigour and production quality. Annals of Applied Biology 150, 237-252.

Chaves, M.M., Zarrouk, O., Francisco, R., Costa, J.M., Santos, T., Regalado, A.P., Rodrigues, M.L., Lopes, C., 2010. Grapevine under deficit irrigation: hints from physiological and molecular data. Annals of Botany 105, 661-676.

Chessel, D., Dufour, A.-B., Thioulouse, J., 2004. The ade4 package-I - one-Table methods. R News 4, 5-1.

COTR, 2008. Centro Operativo e de Tecnologia de Regadio., http://www.cotr.pt.

Culhane, A.C., Perriere, G., Considine, E.C., Cotter, T.G., Higgins, D.G., 2002. Betweengroup analysis of microarray data. Bioinformatics 18, 1600-1608.

Curtin, C., Zhang, W., Franco, C., 2003. Manipulation anthocyanin composition in Vitis vinifera suspension cultures by elicitation with jasmonic acid and light irradiation. Biotechnology Letters 25, 1131-1135.

Czapski, J., Saniewski, M.L., 1992. Stimulation of ethylene production and ethyleneforming enzyme activity in fruits of the non-ripening nor and rin tomato mutants by methyl jasmonate. Journal of Plant Physiology 139, 265-268.

Dai, Z.W., Ollat, N., Gomès, E., Decroocq, S., Tandonnet, J.-P., Bordenave, L., Pieri, P., Hilbert, G., Kappel, C., van Leeuwen, C., Vivin, P., Delrot, S., 2011. Ecophysiological, genetic, and molecular causes of variation in grape berry weight and composition: a review. American Journal of Enology and Viticulture 62, 413-425.

Davies, C., Boss, P., Robinson, S., 1997. Treatment of grape berries, a nonclimacteric fruit with a synthetic auxin, retards ripening and alters the expression of developmentally regulated genes. Plant Physiology 115, 1155-1161.

Deluc, L.G., Quilici, D.R., Decendit, A., Grimplet, J., Wheatley, M.D., Schlauch, K.A., Mérillon, J.M., Cushman, J.C., Cramer, G.R., 2009. Water deficit alters differentially metabolic pathways affecting important flavour and quality traits in grape berries of Cabernet Sauvignon and Chardonnay. BMC Genomics 10, 212.

Downey, M.O., Harvey, J.S., Robinson, S.P., 2003. Analysis of tannins in seeds and skins of Shiraz grapes throughout berry development. Australian Journal of Grape and Wine Research 9, 15-27.

Downey, M.O., Harvey, J.S., Robinson, S.P., 2004. The effect of bunch shading on berry development and flavonoid accumulation in Shiraz grapes. Australian Journal of Grape and Wine Research 10,55-73.

Downey, M.O., Dokoozlian, N.K., Krstic, M.P., 2006. Cultural practice and environmental impacts on the flavonoid composition of grapes and wine: a review of recent research. American Journal of Enology and Viticulture 57, 257-268.

Esteban, M.A., Villanueva, M.J., Lissarrague, J.R., 2001. Effect of irrigation on changes in the anthocyanin composition of the skin of cv. Tempranillo (Vitis vinifera L.) grape berries during ripening. Journal of the Science of Food and Agriculture 81, 409-420.

Flexas, J., Bota, J., Escalona, J.M., Sampol, B., Medrano, H., 2002. Effects of drought on photosynthesis in grapevines under field conditions: an evaluation of stomatal and mesophyll limitations. Functional Plant Biology 29, 461-471.

Gagné, S., Saucier, C., Geny, L., 2006. Composition and cellular localization of tannins in Cabernet Sauvignon skins during growth. Journal of Agricultural and Food Chemistry 54, 9465-9471.

Gatti, M., Civardi, S., Zamboni, M., Ferrari, F., Elothammi, D., Bavaresco, L., 2011. Preliminary results on the effect of cluster thinning on stilbene concentration and antioxidant capacity of Vitis vinifera L. cv. "Barbera" wine. Vitis 50 (1), 43-44.

Girona, J., Marsal, J., Mata, M., Del Campo, J., Basile, B., 2009. Phenological sensitivity of berry growth and composition of Tempranillo grapevines (Vitis vinifera L.) to water stress. Australian Journal of Grape and Wine Research 15, 268-277.

Grimplet, J., Deluc, L.G., Tillett, R.L., Wheatley, M.D., Schlauch, K.A., Cushman, J.C., Cramer, G.R., 2007. Tissue-specific mRNA expression profiling in grape berry tissues. BMC Genomics 8, 187.

Grimplet, J., Wheatley, M.D., Jouira, H.B., Deluc, L.G., Cramer, G.R., Cushman, J.C., 2009. Proteomic and selected metabolite analysis of grape berry tissues under well-watered and water-deficit stress conditions. Proteomics 9, 2503-2528.

Intrigliolo, D.S., Castel, J.R., 2010. Response of grapevine cv. 'Tempranillo' to timing and amount of irrigation: water relations, vine growth, yield and berry and wine composition. Irrigation Science 28, 113-125.

Iriti, M., Faoro, F., 2009. Bioactivity of grape chemicals for human health. Natural Product Communications 4, 611-634.

Kedage, V.V., Tilak, J.C., Dixit, G.B., Devasagayam, T.P.A., Mhatre, M., 2007. A study of antioxidant properties of some varieties of grapes (Vitis vinifera L.). Critical Reviews in Food Science and Nutrition 47, 175-185.
Keller, M., Smithyman, R.P., Mills, L.J., 2008. Interactive effects of deficit irrigation and crop load on Cabernet Sauvignon in an arid climate. American Journal of Enology and Viticulture 59, 221-234.

Kennedy, J.A., Matthews, M.A., Waterhouse, A.L., 2000. Changes in grape seed polyphenols during fruit ripening. Phytochemistry 55, 77-85.

Kennedy, J.A., Hayasaka, Y., Vidal, S., Waters, E.J., Jones, G.P., 2001. Composition of grape skin proanthocyanidins at different stages of berry development. Journal of Agricultural and Food Chemistry 49, 5348-5355.

Kennedy, J.A., Matthews, M.A., Waterhouse, A.L., 2002. Effect of maturity and vine water status on grape skin and wine flavonoids. American Journal of Enology and Viticulture 53, 268-274.

Kondo, S., Fokuda, K., 2001. Changes of jasmonate in grape berries and their possible roles in fruit development. Scientia Horticulturae 91, 275-288.

Koyama, K., Sadamatsu, K., Goto-Yamamoto, N., 2010. Abscisic acid stimulated ripening and gene expression in berry skins of the Cabernet Sauvignon grape. Functional \& Integrative Genomics 10, 367-381.

Kriedemann, P.E., Goodwin, I., 2003. Regulated deficit irrigation and partial rootzone drying. An overview of principles and applications. Irrigation insights no. 3. Land \& Water, Australia, $107 \mathrm{pp}$.

Lacampagne, S., Gagné, S., Gény, L., 2010. Involvement of abscisic acid in controlling the proanthocyanidin biosynthesis pathway in grape skin: new elements regarding the regulation of tannin composition and leucoanthocyanidin reductase (LAR) and anthocyanidin reductase (ANR) activities and expression. Journal of Plant Growth Regulation 29, 81-90.

Lopes, C.M., Santos, T.P., Monteiroa, A., Rodrigues, M.L., Costa, J.M., Chaves, M.M. 2011. Combining cover cropping with deficit irrigation in a Mediterranean low vigor vineyard. Scientia Horticulturae 129, 603-612.

Lovisolo, C., Perrone, I., Carra, A., Ferrandino, A., Flexas, J., Medrano, H., Schubert, A. 2010. Drought-induced changes in development and function of grapevine (Vitis spp.) organs and in their hydraulic and non hydraulic interactions at the whole plant level: a physiological and molecular update. Functional Plant Biology 37, 98-116.

Matthews, M.A., Anderson, M.M., 1988. Fruit ripening in Vitis vinifera L.: responses to seasonal water deficits. American Journal of Enology and Viticulture 39, 313-320.

Matthews, M.M., Thomas, T.R., Shackel, K.A., 2009. Fruit ripening in Vitis vinifera L.: possible relation of véraison to turgor and berry softening. Australian Journal of Grape and Wine Research 15, 278-283.

Mattivi, F., Guzzon, R., Vrhovsek, U., Stefanini, M., Velasco, R., 2006. Metabolite profiling of grape: flavonols and anthocyanins. Journal of Agricultural and Food Chemistry 54, 7692-7702.

McCarthy, M.G., 1997. The effect of transient water deficit on berry development of Shiraz Vitis vinifera L. Australian Journal of Grape and Wine Research 3, 102-108.

McCarthy, M.G., Loveys, B.R., Dry, P.R., Stoll, M., 2002. Regulated deficit irrigation and partial rootzone drying as irrigation management techniques for grapevines. Deficit irrigation practices. FAO Water Reports No. 22. Rome, Italy, pp. 79-87.

Mori, K., Goto-Yamamoto, N., Kitayama, M., Hashizume, K., 2007. Loss of anthocyanin in red-wine grape under high temperature. Journal of Experimental Botany 58, 1935-1945.

Nassiri-Asl, M., Hosseinzadeh, H., 2009. Review of the pharmacological effects of Vitis vinifera (grape) and its bioactive compounds. Phytotherapy Research 23, 1197-1204.

Office International de la Vigne et du Vin (OIV), 1990. Recueil des methodes internationales d'analyse des vins et des mouts (volume 1). pp. 155-158.

Ojeda, H., Andary, C., Kraeva, E., Carbonneau, A., Deloire, A., 2002. Influence of preand postveraison water deficit on synthesis and concentration of skin phenolic compounds during berry growth of Vitis vinifera cv. Shiraz. American Journal of Enology and Viticulture 53, 261-267.

Ou, B., Hampsch-Woodill, M., Flanagan, J., Deemer, E.K., Prior, R.L., Huang, D., 2002. Novel fluorometric assay for hydroxyl radical prevention capacity using fluorescein as the probe. Journal of Agricultural and Food Chemistry 50, 2772-2777.

Owen, S.J., Lafond, M.D., Bowen, P., Bogdanoff, C., Usher, K., Abrams, S.R., 2009. Profiles of abscisic acid and its catabolites in developing Merlot grape (Vitis vinifera) berries. American Journal of Enology and Viticulture 60, 277-284.

Poudel, P.R., Tamura, H., Kataoka, I., Mochioka, R., 2008. Phenolic compounds and antioxidant activities of skin and seeds of five wild grapes and two hybrids native to Japan. Journal of Food Composition and Analysis 21, 622-625.

R Development Core Team, 2011. R: A Language and Environment for Statistical Computing. R Foundation for Statistical Computing, Vienna, Austria, ISBN 3900051-07-0. http://www.R-project.org/.

Roby, G., Harbertson, J.F., Adams, D.A., Matthews, M.A., 2004. Berry size and vine water deficits as factors in winegrape composition: anthocyanins and tannins. Australian Journal of Grape and Wine Research 10, 100-107.

Rodriguez Montealegre, R., Romero Peces, R., Chacon Vozmediano, J.L., Martinez Gascuena, J., Garcia Romero, E., 2006. Phenolic compounds in skin and seeds of ten grape Vitis vinifera varieties grown in a warm climate. Journal of Food Composition and Analysis 19, 687-693.

Ruberto, G., Renda, A., Daquino, C., Amico, V., Spatafora, C., Tringali, C., De Tommasi, N., 2007. Polyphenol constituents and antioxidant activity of grape pomace extracts from five Sicilian red grape cultivars. Food Chemistry 100, 203-210.

Santesteban, L.G., Miranda, C., Royo, J.B., 2011. Regulated deficit irrigation effects on growth, yield, grape quality and individual anthocyanin composition in Vitis vinifera L. cv. 'Tempranillo'. Agricultural Water Management 98, 1171-1179.

Schultz, H.R., 2003. Differences in hydraulic architecture account for near isohydric and anisohydric behaviour of two field-grown Vitis vinifera L. cultivars during drought. Plant Cell Env. 26, 1393-1405. 
Shan, X., Zhang, Y., Peng, W., Wang, Z., Xie, D., 2009. Molecular mechanism for jasmonate-induction of anthocyanin accumulation in Arabidopsis. Journal of Experimental Botany 60, 3849-3860.

Shellie, K.C., 2011. Interactive effects of deficit irrigation and berry exposure aspect on Merlot and Cabernet Sauvignon in an arid climate. American Journal of Enology and Viticulture 62, 462-470.

Singleton, V.L., Rossi, J.A., 1965. Colorimetry of total phenolics with phosphomolybdic-phosphotungstic acid reagents. American Journal of Enology and Viticulture 16, 144-158.

Spayd, S.E., Tarara, J.M., Mee, D.L., Ferguson, J.C., 2002. Separation of sunlight and temperature effects on the composition of Vitis vinifera cv Merlot berries. American Journal of Enology and Viticulture 53, 171-182.

Tarara, J.M., Lee, J., Spayd, S.E., Scagel, C.F., 2008. Berry temperature and solar radiation alter acylation, proportion, and concentration of anthocyanin in Merlot grapes. American Journal of Enology and Viticulture 59, 235-247.

Thioulouse, J., Dray, S., 2009. ade4TkGUI: ade4 Tcl/Tk Graphical User Interface. R Package Version 0.2-5. http://CRAN.R-project.org/package=ade4TkGUI.
Thomas, T.R., Matthews, M.A., Shackel, K.A., 2006. Direct in situ measurement of cell turgor in grape (Vitis vinifera L.) berries during development and in response to plant water deficits. Plant, Cell \& Environment 29, 993-1001.

Tyerman, S.D., Chaves, M.M., Barrieu, F., 2012. Water relations of the grape berry and aquaporins. In: Geros, H., Chaves, M.M., Delrot, S. (Eds.), The biochemistry of the grape berry. Bentham Science Publishers, pp. 3-22.

Wada, H., Matthews, M.A., Shackel, K.A., 2009. Seasonal pattern of apoplastic solute accumulation and loss of cell turgor during ripening of Vitis vinifera fruit under field conditions. Journal of Experimental Botany 60, 1773-1781.

Wheeler, S., Loveys, B., Ford, C., Davies, C., 2009. The relationship between the expression of abscisic acid biosynthesis genes, accumulation of abscisic acid and the promotion of Vitis vinifera L. berry ripening by abscisic acid. Australian Journal of Grape and Wine Research 15, 195-204.

Yilmaz, Y., Toledo, R.T., 2004. Health aspects of functional grape seed constituents. Trends in Food Science \& Technology 15, 422-433. 